[Chem. Pharm. Bull.

$[34(10) 4368-4372(1986)]$

\title{
Saponins of Plants of Panax Species Collected in Central Nepal and Their Chemotaxonomical Significance. II
}

\author{
Toshinobu Morita, ${ }^{a}$ Yun-Cheung Kong, ${ }^{b}$ Paul Pui-Hay But,${ }^{b}$ \\ KAM-HUNG NG, ${ }^{b}$ TAI-TUNG YIP, ${ }^{b}$ RYOJI KASAI ${ }^{a}$ \\ and OSAMU TANAKA*,a \\ Institute of Pharmaceutical Sciences, Hiroshima University School of Medicine, ${ }^{a}$ \\ Kasumi, Minami-ku, Hiroshima 734, Japan and Department of Biochemistry, \\ The Chinese University of Hong Kong, ${ }^{b}$ Shatin NT, Hong Kong
}

(Received May 2, 1986)

\begin{abstract}
A specimen of Panax spp. collected along a trail leading from Dhunche to Singkunba, Central Nepal, was tentatively assigned as P. pseudo-ginseng W ALL. var. elegantior (BURK.) Hoo et TSEUNG (probably identical with $P$. japonicus C. A. MeYer var. major (BuRK.) C. Y. Wu et K.M. FENG). From rhizomes of this specimen, the following saponins were isolated. Dammarane saponins: ginsenosides- $\operatorname{Rg}_{1}(1),-\operatorname{Rg}_{2}(7),-\operatorname{Re}(9),-\operatorname{Rd}(14),-\operatorname{Rb}_{1}(11)$, gypenoside XVII (15) and notoginsenosides-R1 (8) and -R2 (6). Ocotillol type saponins: majonoside-R2 (2), 24(S)-pseudoginsenoside- $F_{11}(3)$ and pseudo-ginsenosides- $R T_{2}(4)$ and $-F_{11}(5)$. Oleanolic acid saponins: pseudoginsenoside- $\mathrm{RT}_{1}(\mathbf{1 2})$ and chikusetsusaponins-IVa (10) and -V (13). A new saponin, named pseudoginsenoside- $\mathrm{RS}_{1}(\mathbf{1 6})$ was also isolated and formulated as monoacetyl-ginsenoside- Re. The saponin compositions of this specimen and other Panax spp. are discussed from the viewpoints of chemotaxonomy and pharmacognosy.
\end{abstract}

Keywords_-Nepal; Panax species; Panax pseudo-ginseng; Himalayan medicinal plant; Araliaceae; saponin; ginsenoside- $\mathrm{RS}_{1}$; ginsenoside- $\mathrm{Re}$; dammarane; acetylated saponin

In connection with chemotaxonomical studies on Panax spp., identification of saponins from rhizomes of plants of this genus collected near Annapurna was recently reported. ${ }^{1)}$ In July 1985, P. But and Y. C. Kong collected plants. of this genus along a trail leading from Dhunche to Singkunba, Nepal at altitudes around $2500 \mathrm{~m}$. The present paper deals with the isolation and identification of saponins from rhizomes of this specimen and discusses its chemotaxonomical characteristics in comparison with those of other related plants.

The dried rhizomes $(80 \mathrm{~g})$ were extracted with hot methanol and then with hot $50 \%$ aqueous methanol. The combined extract was concentrated to dryness and the residue was subjected to column chromatography on highly porous polymer, which separated the saponin mixture $(8.9 \mathrm{~g})$ from other substances. This saponin mixture was further separated by chromatography to give fifteen saponins, which have already been isolated from other Panax spp. ${ }^{2)}$ These are as follows (yield \% from the dried rhizomes is shown in parenthesis): ginsenoside- $\mathrm{Rg}_{1}{ }^{3)}(1,0.3 \%)$, majonoside- $2^{4)}(2,0.1 \%), 24(S)$-pseudo-ginsenoside- $\mathrm{F}_{11}{ }^{1)}(3$, $0.06 \%$ ), pseudo-ginsenoside- $\mathrm{RT}_{2}{ }^{5)}(4,0.02 \%)$, pseudo-ginsenoside- $\mathrm{F}_{11}{ }^{6)}(5,0.01 \%)$, notoginsenoside- $2^{7)}(6,0.09 \%)$, ginsenoside- $\mathrm{Rg}_{2}{ }^{8)}(7,0.03 \%)$, notoginsenoside- $\mathrm{R} 1^{7)}(8,0.2 \%)$, ginsenoside- $\operatorname{Re}^{8)}(\mathbf{9}, 0.3 \%)$, chikusetsusaponin-IVa' $(\mathbf{1 0}, 0.04 \%)$, ginsenoside- $\mathrm{Rb}_{1}^{\text {(10) }}(\mathbf{1 1}$, $0.7 \%)$, pseudo-ginsenoside-RT ${ }_{1}^{5)}(12,0.4 \%)$, chikusetsusaponin- $\mathrm{V}^{11)} \quad(13$, = ginsenosideRo, ${ }^{10)} 0.5 \%$ ), ginsenoside-Rd ${ }^{10)}(14,0.1 \%)$ and gypenoside-XVII ${ }^{12)}(15,0.08 \%)$.

Together with these known saponins, a new saponin named pseudo-ginsenoside- $\mathrm{RS}_{1}(\mathbf{1 6})$ was also isolated in a yield of $0.02 \%$. Glucose and rhamnose were identified in the acid hydrolysate of 16. The presence of an acetoxyl group in $\mathbf{1 6}$ was shown by carbon-13 nuclear 
magnetic resonance $\left({ }^{13} \mathrm{C}-\mathrm{NMR}\right)$ signals at $\delta 20.8$ and 170.6 and a proton nuclear magnetic resonance $\left({ }^{1} \mathrm{H}-\mathrm{NMR}\right)$ signal at $\delta 2.04(3 \mathrm{H}, \mathrm{s})$. On alkaline hydrolysis, 16 afforded 9 . In the ${ }^{13} \mathrm{C}-\mathrm{NMR}$ spectrum of 16 , signals due to the aglycone moiety were almost superimposable on those of 9 except for slight displacement of the C-6 signal (Table I). The electron impact-mass spectrum (EI-MS) of trimethylsilylated (TMSi) 16 exhibited ions at $m / z 711$ [(GlcRha)Ac· $\mathrm{TMSi}_{5}$ ], 621 (711-TMSiOH), 451 [(terminal Glc)TMSi ${ }_{4}$ ], 361 (451-TMSiOH), 363 [(terminal Rha) $\mathrm{TMSi}_{3}$ ] and $273(363-\mathrm{TMSiOH})$, indicating that the acetoxyl group of 16 is located on the inner glucosyl unit of the 6-O-rhamnosyl-glucosyl moiety of 9. Among the carbon resonances due to two $\beta$-glucopyranosyl units, on going from 9 to 16, one C-6 signal was deshielded and one C-5 signal was shielded, while other carbon signals due to the sugar moieties remained unshifted (Table I). Based on these findings, 16 can be formulated as a monoacetate of 9 , in which the acetyl group is located at the 6-hydroxyl group of the inner $\beta$ glucopyranosyl unit of the 6-O-glycosyl moiety.

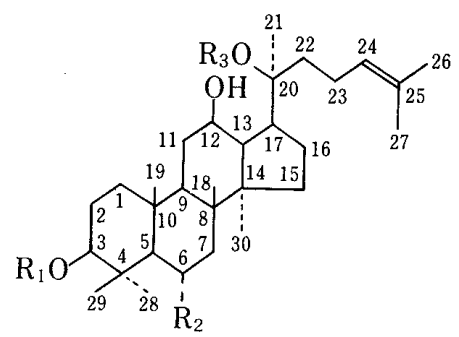

\begin{tabular}{|c|c|c|c|}
\hline & $\mathrm{R}_{1}$ & $\mathrm{R}_{2}$ & $\mathrm{R}_{3}$ \\
\hline 1: & $-\mathrm{H}$ & $-\mathrm{O}-\mathrm{Glc}$ & - Glc \\
\hline 6: & $-\mathrm{H}$ & $-\mathrm{O}-\mathrm{Glc} \stackrel{2}{-} \mathrm{Xyl}$ & $-\mathrm{H}$ \\
\hline 8: & $-\mathrm{H}$ & $-\mathrm{O}-\mathrm{Glc}^{2}-\mathrm{Xyl}$ & $-\mathrm{Glc}$ \\
\hline 7: & $-\mathrm{H}$ & $-\mathrm{O}-\mathrm{Glc} \stackrel{2}{-} \mathrm{Rha}$ & $-\mathrm{H}$ \\
\hline 9: & $-\mathbf{H}$ & - $-\mathrm{Glc}^{2}-\mathrm{Rha}$ & - Glc \\
\hline 16: & $-\mathrm{H}$ & $-\mathrm{O}-\mathrm{Glc}_{6}^{2 / \mathrm{Rha}}$ & - Glc \\
\hline $11:$ & $-\mathrm{Glc}^{2}-\mathrm{Glc}$ & $-\mathbf{H}$ & $-\mathrm{Glc} \stackrel{6}{-} \mathrm{Glc}$ \\
\hline 14: & 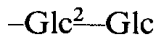 & $-\mathrm{H}$ & -Glc \\
\hline 15: & - Glc & $-\mathrm{H}$ & $-\mathrm{Glc}=\mathrm{Glc}$ \\
\hline
\end{tabular}

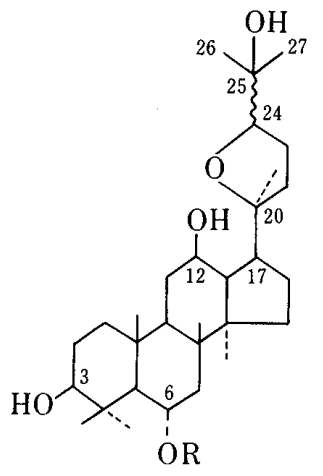

$\mathbf{R}$

2: $-\mathrm{Glc} 2 \mathrm{Xyl} 24(S)$

4: $-\mathrm{Glc}^{2}-\mathrm{Xyl} 24(R)$

3: - Glc $^{2}$-Rha 24(S)

5: -Glc ${ }^{2}$ - Rha $24(R)$

Ac: acetyl

Glc: $\beta$-D-glucopyranosyl

GlcUA : $\quad \beta$-D-glucuronic acid

Rha: $\alpha$-L-rhamnopyranosyl

$\mathrm{Xyl}$ : $\quad \beta$-D-xylopyranosyl

Chart 1

It has been disclosed that roots and small rhizomes of $P$. ginseng C. A. MEYER, ${ }^{2)} P$. quinquefolium L. (American Ginseng) ${ }^{13)}$ and P. notoginseng (BURK.) F. H. CHEN (SanchiGinseng) ${ }^{7,14)}$ which have a carrot-like root, contain a variety of dammarane saponins such as $1,9,11$ and 14 with either a small amount of the oleanolic acid saponin, 13, or none (SanchiGinseng).

On the other hand, Panax spp. having a large rhizome are distributed from the Himalayan region to Japan through the South West province of China. These are $P$. japonicus C. A. MeYer (Japan and China), ${ }^{9,10,15,16)}$ P. japonicus C. A. MEYER var. major (BURK.) C. Y. WU et K. M. FENG (China) ${ }^{4)} P$. zingiberensis $\mathrm{C}$. Y. WU et K. M. FENG (China) ${ }^{17)} P$. japonicus C. A. MEYER var. angustifolius (BURK.) CHENG et CHU (China), ${ }^{18)}$ P. stipuleanatus H. T. TSAI et K. M. FENG (China) ${ }^{19)}$ and P. pseudo-ginseng WALL. subsp. himalaicus HARA and its varieties ${ }^{20)}\left(\mathrm{Bhutan}^{5,21)}\right.$ and $\left.\mathrm{Nepal}^{1)}\right)$, etc. It has been revealed that the saponin composition of rhizomes of most of these Japanese, Chinese and Bhutanese specimens includes a large amount of oleanolic acid saponins such as $\mathbf{1 3}$ together with the dammarane 
TABLE I. ${ }^{13} \mathrm{C}-\mathrm{NMR}$ Chemical Shifts (in $\mathrm{C}_{5} \mathrm{D}_{5} \mathrm{~N}$ )

\begin{tabular}{|c|c|c|c|c|c|}
\hline \multicolumn{3}{|c|}{ Aglycone moieties } & \multicolumn{3}{|c|}{ Sugar moieties } \\
\hline & 9 & 16 & & 9 & 16 \\
\hline C-1 & 39.6 & 39.7 & 6-Glc 1 & 101.8 & 101.3 \\
\hline $\mathrm{C}-2$ & 27.6 & 27.7 & 2 & 79.1 & 79.0 \\
\hline $\mathrm{C}-3$ & 78.1 & 78.3 & 3 & 78.1 & 78.3 \\
\hline $\mathrm{C}-4$ & 39.9 & 39.8 & 4 & $72.5^{a)}$ & 72.2 \\
\hline $\mathrm{C}-5$ & 60.8 & 60.6 & 5 & 78.1 & 75.4 \\
\hline$C-6$ & 74.5 & 73.5 & 6 & 63.0 & 64.9 \\
\hline $\mathrm{C}-7$ & 45.9 & 46.1 & Rha 1 & 101.8 & 101.9 \\
\hline C-8 & 41.1 & 41.2 & 2 & $72.3^{a)}$ & 72.2 \\
\hline $\mathrm{C}-9$ & 49.5 & 49.5 & 3 & $72.3^{a)}$ & 72.2 \\
\hline $\mathrm{C}-10$ & 39.6 & 39.7 & 4 & 74.0 & 74.0 \\
\hline C-11 & 30.7 & 30.8 & 5 & 69.4 & 69.3 \\
\hline $\mathrm{C}-12$ & 70.1 & 70.1 & 6 & 18.7 & 18.6 \\
\hline $\mathrm{C}-13$ & 49.0 & 49.1 & 20-Glc 1 & 98.2 & 98.2 \\
\hline C-14 & 51.4 & 51.4 & 2 & 75.0 & 75.0 \\
\hline C-15 & 30.7 & 30.8 & 3 & 79.1 & 79.0 \\
\hline C-16 & 26.6 & 26.6 & 4 & 71.5 & 71.5 \\
\hline C-17 & 51.6 & 51.6 & 5 & 78.1 & 78.3 \\
\hline C-18 & $17.5^{a)}$ & $17.3^{a)}$ & 6 & 62.8 & 62.8 \\
\hline C-19 & $17.5^{a)}$ & $17.6^{a)}$ & $\mathrm{CH}_{3} \mathrm{CO}$ & - & 20.8 \\
\hline $\mathrm{C}-20$ & 83.2 & 83.2 & $\overline{\mathrm{C}} \mathrm{H}_{3} \mathrm{CO}$ & - & 170.6 \\
\hline C-21 & 22.3 & 22.2 & & & \\
\hline C-22 & 36.0 & 36.0 & & & \\
\hline C-23 & 23.2 & 23.2 & & & \\
\hline C-24 & 125.9 & 125.9 & & & \\
\hline $\mathrm{C}-25$ & 130.8 & 130.8 & & & \\
\hline $\mathrm{C}-26$ & 25.7 & 25.7 & & & \\
\hline$C-27$ & $17.7^{a)}$ & $17.7^{a)}$ & & & \\
\hline C-28 & 32.1 & 32.0 & & & \\
\hline C-29 & $17.2^{a)}$ & $17.3^{a)}$ & & & \\
\hline$C-30$ & $17.2^{a)}$ & $17.3^{a)}$ & & & \\
\hline
\end{tabular}

Glc, $\beta$-D-glucopyranosyl; Rha, $\alpha$-L-rhamnopyranosyl. a) Assignments in any column may be interchanged, though those given here are preferred.

saponins, ${ }^{2)}$ except for $P$. stipuleanatus. ${ }^{19)} P$. stipuleanatus grows at the southern limit of the distribution of this genus (South Yunnan, China and North Vietnum). From the rhizomes of this plant, the characteristic oleanolic acid saponins, stipuleanosides $R_{1}$ and $R_{2}$, have been isolated but no dammarane saponins have been obtained.

Recently, it was found that in contrast to these specimens, rhizomes of plants (tentatively named specimens $\mathrm{C}$ and $\mathrm{G}$ ) collected near Annapurna, Nepal, contain a large amount of dammarane saponins but no oleanolic acid saponin could be detected. ${ }^{1)}$ It is noted that these specimens were growing near the western limit of the distribution of Panax spp. and their saponin compositions are very similar to that of Sanchi-Ginseng. The specimen of the present study was collected somewhat to the east of the locations where specimens $\mathrm{C}$ and $\mathrm{G}$ were collected. It is noteworthy that the saponin composition of the present specimen seems to be intermediate between those of specimens $\mathrm{C}$ and $\mathrm{G}^{1)}$ and specimens growing in Bhutan, China and Japan; both the oleanolic acid saponins and dammarane saponins were isolated but in contrast to the Japanese, Chinese and Bhutanese specimens, the content of the former $(\mathbf{1 0}, \mathbf{1 2}$ and 13) is somewhat less than that of the latter $(1-9,11$ and $14-16)$.

Since a variety of biological activities of dammarane saponins have been reported, ${ }^{22)}$ the 
characteristic saponin compositions in the specimens growing in central Nepal are significant from the viewpoint of pharmacological utility.

The present specimen is tentatively assigned as $P$. pseudo-ginseng WALL. var. elegantior (BURK.) HOO et TSEUNG, which would be identical with $P$. japonicus var. major reported by the taxonomists of Kunming Institute of Botany, Academia Sinica. ${ }^{23)}$ Further taxonomical correlation of Himalayan Panax spp. to the Chinese and Japanese specimens is in progress.

\section{Experimental}

General Procedures - - NMR spectra were taken on a JEOL FX-100 $\left({ }^{1} \mathrm{H}-\mathrm{NMR}\right.$ at $99.55 \mathrm{MHz}$ and ${ }^{13} \mathrm{C}-\mathrm{NMR}$ at $25.00 \mathrm{MHz}$ ) spectrometer in $\mathrm{C}_{5} \mathrm{D}_{5} \mathrm{~N}$ (or DMSO- $d_{6}$ ) with tetramethylsilane (TMS) as an internal standard. Mass spectra (MS) were recorded on a JEOL 01-SG-2 mass spectrometer at $75 \mathrm{eV}$. Optical rotations were measured with a Union PM-101 automatic digital polarimeter at 13 or $15^{\circ} \mathrm{C}$ in $\mathrm{MeOH}$. Melting points were determined on a Yanaco micro hot stage and are uncorrected.

Identification of the Known Saponins: Each known saponin was identified by thin layer chromatography (TLC) under the various conditions as well as by comparison of the ${ }^{1} \mathrm{H}$-and ${ }^{13} \mathrm{C}$-NMR spectra, optical rotation and MS (as the acetate or trimethylsilyl ether) with those of the corresponding authentic sample as described in the preceding paper. ${ }^{1)}$

High Performance Liquid Chromatography (HPLC) Equipment: LC-3A pump (Shimadzu); detector, RI-8000 (Toyo Soda).

Elemental analysis of the new saponin, 16, was not done since we wished to preserve the authentic sample obtained from the limited amount of Himalayan plant materials for future studies.

Plant Material — The specimen was collected along a trail leading from Dhunche to Singkunba, Nepal, at altitudes around $2500 \mathrm{~m}$ on July 10,1985 , and samples have been deposited in the Herbarium of the Department of Biology, the Chinese University of Hong Kong (P. But and Y. C. Kong 85-101) and in the Herbarium of the Department of Biology, Zhongshan University, Guangzhou, China (H. T. Chang 30142).

Extraction and Separation of Saponins - - The dried and powdered rhizomes $(80 \mathrm{~g})$ were extracted with $\mathrm{MeOH}$ $(400 \mathrm{ml} \times 4)$ and then with hot $50 \% \mathrm{MeOH}(400 \mathrm{ml} \times 2)$ to give an $\mathrm{MeOH}$ extract (after concentration) in a yield of $30 \%$. An aqueous solution of this $\mathrm{MeOH}$ extract was subjected to column chromatography on reversed-phase highly porous polymer (Kogel B-G 4600, Beads 60-80 mesh, Shoko-Tsusho Co., Ltd.) (solvent; 10\% $\mathrm{MeOH}$ (31), $\mathrm{MeOH}$ (3l) and finally $\mathrm{CHCl}_{3}(21)$ ) to provide the $10 \% \mathrm{MeOH}$ eluate $(13.5 \mathrm{~g}), \mathrm{MeOH}$ eluate (crude saponin fraction) $(8.9 \mathrm{~g})$ and $\mathrm{CHCl}_{3}$ eluate $(390 \mathrm{mg}$ ). This $\mathrm{MeOH}$ eluate was separated into three fractions, fr- $1,-2$ and -3 , by column chromatography on silylated silica gel (LiChroprep RP-8, Merck) (solvent; 60 to $70 \% \mathrm{MeOH}$ ).

$\mathrm{Fr}-1$ was separated into two fractions, fr-1 a and fr- $1 \mathrm{~b}$, by column chromatography on silica gel (solvent; $\mathrm{CHCl}_{3}-$ $\mathrm{MeOH}-\mathrm{H}_{2} \mathrm{O}(6: 4: 1$, homogeneous)). Fr-1a was further separated into two fractions, fr-1a-1 and fr-1a-2, by column chromatography on silica gel (solvent; $\mathrm{CHCl}_{3}-\mathrm{MeOH}-\mathrm{H}_{2} \mathrm{O}(30: 10: 1$, homogeneous)). Fr-1a-1 was chromatographed on silylated silica gel (vide supra) (solvent; $70 \% \mathrm{MeOH})$ to give fr-1a-1-1, fr-1a-1-2, $6(0.09 \%$ yield) and 7 $\left(0.03 \%\right.$ yield). 6; colorless prisms (from $\left.\mathrm{MeOH}-\mathrm{H}_{2} \mathrm{O}\right), \mathrm{mp} 185-187^{\circ} \mathrm{C},[\alpha]_{\mathrm{D}}^{13}+13.8^{\circ}(c=1.34, \mathrm{MeOH}) .7$; colorless needles (from EtOH), mp 185-187 ${ }^{\circ} \mathrm{C},[\alpha]_{\mathrm{D}}^{13}-15.2^{\circ}(c=0.77, \mathrm{MeOH})$. Fr-1 a-1-1 was further chromatographed on silylated silica gel (vide supra) (solvent; $57 \% \mathrm{MeOH}$ ) to give a mixture of $\mathbf{1 , 2}$ and 3 and crude 16. This mixture, after repeated column chromatography on silylated silica gel (vide supra) (solvent; $53 \% \mathrm{MeOH}$ ), gave crude $\mathbf{1}$ and a mixture of $\mathbf{2}$ and 3. Crude $\mathbf{1}$ was finally purified by column chromatography on silica gel (solvent; $\mathrm{CHCl}_{3}-\mathrm{MeOH}-$ $\mathrm{H}_{2} \mathrm{O}(37: 10: 1$, homogeneous) $)$ to give $1\left(0.3 \%\right.$ yield), a white powder (MeOH-EtOAc), $[\alpha]_{\mathrm{D}}^{13}+33.1^{\circ}(c=1.63$, $\mathrm{MeOH}$ ). The mixture of $\mathbf{2}$ and $\mathbf{3}$ was subjected to preparative HPLC on a reversed-phase column of ODS-120A (Toyo Soda) $(21.5 \mathrm{~mm} \times 30 \mathrm{~cm}$; mobile phase, $55 \% \mathrm{MeOH}$; flow rate, $8.0 \mathrm{ml} / \mathrm{min}$; injection vol., $0.9 \mathrm{ml}(172 \mathrm{mg} / 1.8 \mathrm{ml} 55 \%$ $\mathrm{MeOH})$; detection, RI) to give $2\left(0.1 \%\right.$ yield) and $3(0.06 \%$ yield $) .2$, a white powder $(\mathrm{MeOH}-\mathrm{EtOAc}),[\alpha]_{\mathrm{D}}^{15}-2.4^{\circ}$ $(c=1.43, \mathrm{MeOH}) .3$, a white powder $(\mathrm{MeOH}-\mathrm{EtOAc}),[\alpha]_{\mathrm{D}}^{15}-24.8^{\circ}(c=1.33, \mathrm{MeOH})$.

Crude 16 was finally purified by column chromatography on silica gel (solvent; $\mathrm{CHCl}_{3}-\mathrm{MeOH}-\mathrm{H}_{2} \mathrm{O}(30: 10: 1$, homogeneous $))$ to give $16\left(0.02 \%\right.$ yield) as a white powder (MeOH-EtOAc), $[\alpha]_{\mathrm{p}}^{15}+1.6^{\circ}(c=0.93, \mathrm{MeOH})$.

Fr-1a-1-2 was subjected to preparative HPLC on a reversed-phase column of ODS-120A (vide supra) $(21.5 \mathrm{~mm} \times 30 \mathrm{~cm}$; mobile phase, $55 \% \mathrm{MeOH}$; flow rate, $8.5 \mathrm{ml} / \mathrm{min}$; injection vol., $0.5 \mathrm{ml}(32 \mathrm{mg} / 0.5 \mathrm{ml} 55 \% \mathrm{MeOH})$; detection, RI) to give $4\left(0.02 \%\right.$ yield) as a white powder (MeOH-EtOAc), $[\alpha]_{\mathrm{D}}^{15}+9.4^{\circ}(c=0.62, \mathrm{MeOH})$ and $\mathbf{5}(0.01 \%$ yield), a white powder ( $\mathrm{MeOH}-\mathrm{EtOAc}),[\alpha]_{\mathrm{D}}^{15}-17.7^{\circ}(c=0.52, \mathrm{MeOH})$. Fr-1a-2 was subjected to preparative HPLC on a reversed-phase column of ODS-120A (vide supra) $(21.5 \mathrm{~mm} \times 30 \mathrm{~cm}$; mobile phase, $55 \% \mathrm{MeOH}$; flow rate, $6.8 \mathrm{ml} / \mathrm{min}$; injection vol., $0.9 \mathrm{ml}(398 \mathrm{mg} / 3.6 \mathrm{ml} 55 \% \mathrm{MeOH})$; detection, $\mathrm{RI})$ to give $8(0.2 \%$ yield $)$ as colorless needles (from $\mathrm{MeOH}-\mathrm{H}_{2} \mathrm{O}$ ), $\mathrm{mp} 213-215^{\circ},[\alpha]_{\mathrm{b}}^{15 .}+12.6^{\circ}(c=1.07, \mathrm{MeOH})$ and $9(0.3 \%$ yield) as colorless needles (from $50 \%$ $\mathrm{MeOH}), \mathrm{mp} 203-205^{\circ},[\alpha]_{\mathrm{D}}^{15}-4.5^{\circ}(c=1.28, \mathrm{MeOH})$.

Fr-1b was separated into two fractions, fr-1b-1 and fr-1b-2, by column chromatography on silica gel (solvent; 
$\mathrm{CHCl}_{3}-\mathrm{MeOH}-\mathrm{H}_{2} \mathrm{O}(65: 35: 10$, lower layer $)$ and $\mathrm{CHCl}_{3}-\mathrm{MeOH}-\mathrm{H}_{2} \mathrm{O}(6: 4: 1$, homogeneous $\left.)\right)$. Fr-1 b- 1 was further chromatographed on silylated silica gel (vide supra) (solvent; $65 \% \mathrm{MeOH}$ ) to give $10(0.04 \%$ yield) as colorless needles (from $\left.\mathrm{MeOH}-\mathrm{H}_{2} \mathrm{O}\right), \mathrm{mp} 211-213^{\circ} \mathrm{C}(\mathrm{dec}),.[\alpha]_{\mathrm{D}}^{15}+30.5^{\circ}(c=1.49, \mathrm{MeOH})$ and $11(0.7 \%$ yield) as a white powder $(\mathrm{MeOH}-\mathrm{EtOAc}),[\alpha]_{\mathrm{D}}^{15}+8.8^{\circ}(c=1.02, \mathrm{MeOH})$. Fr-1b-2, after repeated column chromatography on silica gel (solvent, $\mathrm{CHCl}_{3}-\mathrm{MeOH}-\mathrm{H}_{2} \mathrm{O}(6: 4: 1$, homogeneous)), followed by deionization with ion exchange resin (Amberlite MB-3), afforded $12\left(0.4 \%\right.$ yield) and $13(0.5 \%$ yield $) .12$; a white powder (MeOH-EtOAc), $[\alpha]_{\mathrm{D}}^{13}+6.1^{\circ}(c=1.07$, $\mathrm{MeOH}) .13$; a white powder (MeOH-EtOAc), $[\alpha]_{\mathrm{D}}^{13}+3.9^{\circ}(c=1.08, \mathrm{MeOH})$.

Fr-2 was purified by column chromatography on silica gel (solvent; $\mathrm{CHCl}_{3}-\mathrm{MeOH}-\mathrm{H}_{2} \mathrm{O}(30: 10: 1$, homogeneous)) to give $14\left(0.1 \%\right.$ yield) as a white powder (from MeOH-EtOAc), $[\alpha]_{\mathrm{D}}^{15}+22.0^{\circ}(c=1.40, \mathrm{MeOH})$.

Fr-3 was purified by column chromatography on silica gel (solvent; $\mathrm{CHCl}_{3}-\mathrm{MeOH}-\mathrm{H}_{2} \mathrm{O}(25: 10: 1$, homogeneous)) to give $15\left(0.08 \%\right.$ yield) as a white powder (from MeOH-EtOAc), $[\alpha]_{\mathrm{D}}^{13}+16.8^{\circ}(c=1.43, \mathrm{MeOH})$.

Hydrolysis of 16, and Identification of the Resulting Monosaccharides_- 16 (a few mg) was heated with $10 \% \mathrm{HCl}$ in $\mathrm{H}_{2} \mathrm{O}$-dioxane $(1: 1)$ in a sealed micro-tube at $80^{\circ} \mathrm{C}$ for $2 \mathrm{~h}$. The reaction mixture was concentrated to dryness by blowing $\mathrm{N}_{2}$ gas over it at room temperature. For analysis by gas-liquid chromatography (GLC), the residue was trimethylsilylated with trimethylsilylimidazole. GLC: On a Shimadzu GC-6A gas chromatograph; glass column of $2 \%$ SE-30 on Chromosorb W (AW-DMCS), $2.6 \mathrm{~mm} \times 2 \mathrm{~m}$; detector, flame ionization detector (FID); injection temperature, $200^{\circ} \mathrm{C}$; column temperature, $155^{\circ} \mathrm{C}$; carrier gas, $\mathrm{N}_{2}(40 \mathrm{ml} / \mathrm{min})$. TMSi-glucose and TMSi-rhamnose were identified by comparison of the retention times with those of authentic samples.

Saponification of 16-16 (a few mg) was heated with $5 \%$ methanolic $\mathrm{KOH}(5 \mathrm{drops})$ at $80{ }^{\circ} \mathrm{C}$ for $5 \cdot \mathrm{min}$. The reaction mixture was neutralized with Amberlite MB-3. In this solution, 9 was identified by TLC on Kieselgel $60 \mathrm{~F}_{254}$ (Merck) with $\mathrm{CHCl}_{3}-\mathrm{MeOH}-\mathrm{H}_{2} \mathrm{O}\left(6: 4: 1\right.$, homogeneous) and with $\mathrm{CHCl}_{3}-\mathrm{BuOH}_{-} \mathrm{MeOH}-\mathrm{H}_{2} \mathrm{O}(20: 40: 15: 20$, lower layer), and by reversed-phase TLC on silica gel plates (RP-8 $\mathrm{F}_{254 \mathrm{~S}}$ (Merck)) with $65 \% \mathrm{MeOH}$ (detection, $\mathrm{H}_{2} \mathrm{SO}_{4}$ ).

\section{References}

1) T. Namba, K. Matsushige, T. Morita and O. Tanaka, Chem. Pharm. Bull., 34, 730 (1986).

2) O. Tanaka and R. Kasai, "Fortschritte der Chemie organischer Naturstoffe," Vol. 46, ed. by W. Herz, H. Griesebach, G. W. Kirby and Ch. Tamm, Springer-Verlag, Vienna, New York, 1984, pp. 1-76; O. Tanaka, Yakugaku Zasshi, 105, 323 (1985).

3) Y. Nagai, O. Tanaka and S. Shibata, Tetrahedron, 27, 881 (1971).

4) T. Morita, R. Kasai, O. Tanaka, J. Zhou, T. Yang and J. Shoji, Chem. Pharm. Bull., 30, 4341 (1982).

5) O. Tanaka, T. Morita, R. Kasai, J. Kinouchi, S. Sanada, Y. Ida and J. Shoji, Chem. Pharm. Bull., 33, 2323 (1985).

6) O. Tanaka and S. Yahara, Phytochemistry, 17, 1353 (1978).

7) J. Zhou, M. Wu, S. Taniyasu, H. Besso, O. Tanaka, Y. Saruwatari and T. Fuwa, Chem. Pharm. Bull., 29, 2844 (1981).

8) S. Sanada, N. Kondo, J. Shoji, O. Tanaka and S. Shibata, Chem. Pharm. Bull., 22, 2408 (1974).

9) T. D. Lin, N. Kondo and J. Shoji, Chem. Pharm. Bull., 24, 253 (1976).

10) S. Sanada, N. Kondo, J. Shoji, O. Tanaka and S. Shibata, Chem. Pharm. Bull., 22, 421 (1974).

11) N. Kondo, Y. Marumoto and J. Shoji, Chem. Pharm. Bull., 19, 1103 (1971).

12) T. Takemoto, S. Arihara, T. Nakajima, and M. Okuhira, Yakugaku Zasshi, 103, 1015 (1983).

13) H. Besso, R. Kasai, J. Wei, J. Wang, Y. Saruwatari, T. Fuwa and O. Tanaka, Chem. Pharm. Bull., 30, 4534 (1982) and references cited therein.

14) H. Matsuura, R. Kasai, O. Tanaka, Y. Saruwatari, T. Fuwa and J. Zhou, Chem. Pharm. Buill., 31, 2281 (1983) and references cited therein.

15) T. Morita, R. Kasai, H. Kohda, O. Tanaka, J. Zhou and T. Yang, Chem. Pharm. Bull., 31, 3205 (1983).

16) T. Morita, O. Tanaka and H. Kohda, Chem. Pharm. Bull., 33, 3852 (1985).

17) C. Yang, Z. Jiang, M. Wu, J. Zhou and O. Tanaka, Yiao Xue Tong Bao, 19, 232 (1984).

18) C. Wang, Z. Jia, T. Chu, C. Yang, J. Zhou, R. Kasai and O. Tanaka, Acta Botanica Sinica, 27, 618 (1985).

19) C. Yang, Z. Jiang, J. Zhou, R. Kasai and O. Tanaka, Acta Botanica Yunnanica, 7, 103 (1985).

20) H. Hara, J. Jap. Bot., 45, 197 (1970).

21) N. Kondo, J. Shoji and O. Tanaka, Chem. Pharm. Bull., 21, 2702 (1973); N. Kondo and J. Shoji, ibid., 23, 3282 (1975).

22) S. Shibata, O. Tanaka, J. Shoji and H. Saito, "Economic and Medicinal Plant Research," Vol. 1, ed. by H. Wagner, H. Hikino and N. R. Farnthworth, Academic Press, London, Orlando, San Diego, New York, Toronto, Montreal, Sydney and Tokyo, 1985, pp. 218-284.

23) J. Zhou, W. Huang, M. Wu, T. Yang, G. Feng and C. Wu, Acta Phytotaxonomica Sinica, 13, 29 (1975). 